\title{
Thermodynamic Studies of Ionic Interactions in Aqueous Solutions of Imidazolium-Based Ionic Liquids [Emim] [Br] and [Bmim][Cl]
}

\author{
Ramesh L. Gardas, ${ }^{\dagger, \downarrow}$ Dilip H. Dagade, ${ }^{\dagger}$ João A. P. Coutinho, ${ }^{\ddagger}$ and Kesharsingh J. Patil ${ }^{*}, \dagger$ \\ Department of Chemistry, Shivaji University, Kolhapur 416 004, India, and CICECO, Departamento de \\ Química, Universidade de Aveiro, 3810-193 Aveiro, Portugal
}

Received: October 26, 2007; In Final Form: December 13, 2007

\begin{abstract}
Experimental measurements of density at different temperatures ranging from 293.15 to $313.15 \mathrm{~K}$, the speed of sound and osmotic coefficients at $298.15 \mathrm{~K}$ for aqueous solution of 1-ethyl-3-methylimidazolium bromide ([Emim][Br]), and osmotic coefficients at $298.15 \mathrm{~K}$ for aqueous solutions of 1-butyl-3-methylimidazolium chloride $([\mathrm{Bmim}][\mathrm{Cl}])$ in the dilute concentration region are taken. The data are used to obtain compressibilities, expansivity, apparent and limiting molar properties, internal pressure, activity, and activity coefficients for $[$ Emim $][\mathrm{Br}]$ in aqueous solutions. Experimental activity coefficient data are compared with that obtained from Debye-Hückel and Pitzer models. The activity data are further used to obtain the hydration number and the osmotic second virial coefficients of ionic liquids. Partial molar entropies of [Bmim] [Cl] are also obtained using the free-energy and enthalpy data. The distance of the closest approach of ions is estimated using the activity data for ILs in aqueous solutions and is compared with that of X-ray data analysis in the solid phase. The measured data show that the concentration dependence for aqueous solutions of [Emim] [Br] can be accounted for in terms of the hydrophobic hydration of ions and that this IL exhibits Coulombic interactions as well as hydrophobic hydration for both the cations and anions. The small hydration numbers for the studied ILs indicate that the low charge density of cations and their hydrophobic nature is responsible for the formation of the water-structure-enforced ion pairs.
\end{abstract}

\section{Introduction}

Ionic liquids (ILs) have seized the imagination of the scientific community due to their unique properties such as low melting temperature, large liquidus range, negligible vapor pressure, nonflammability, high thermal stability, and very rich and complex behavior as solvents. Moreover, their physicochemical properties can be finely tuned by the appropriate selection of the cation and/or anion. ${ }^{1,2}$ Although ILs are water stable and having significant practical implications, some of them are hygroscopic. ${ }^{3}$ The presence of low fractions of water in the IL phase can dramatically affect their physical properties ${ }^{4-10}$ and may also affect the rates and selectivity of reactions involving or carried in ILs. ${ }^{11}$ Water may also act as a cosolvent to increase the mutual solubility between alcohols and ILs or as an antisolvent to reduce the solubility of gases in ILs. ${ }^{12-14}$

Ionic liquids can be hydrophobic or hydrophilic depending on the structures of the cation and/or anion. ${ }^{12,15}$ Hydrophilic ionic liquids may fully or partially dissociate into ions when mixed with water, which is similar to what is observed in regular aqueous solutions of inorganic salts. These ions are solvated in aqueous solutions, causing structural changes to the aqueous environment ${ }^{16,17}$ which have been explained by many workers using the Frank and Wen cluster model. ${ }^{18}$ In this respect, Desnoyers et al. have studied various thermodynamic properties of model compounds like alkali halides and tetraalkylammonium salts in aqueous as well as mixed aqueous solutions. ${ }^{19}$ Freidman et al. have also made theoretical developments using the Gurney

\footnotetext{
* To whom correspondence should be addressed. E-mail patilkesharsingh@hotmail.com.

$\dagger$ Shivaji University.

$\doteqdot$ Universidade de Aveiro.
}

cosphere effect to account for the osmotic and activity coefficient properties in detail. ${ }^{20,21}$ In solution, the solvation and the interactions of the ions or ion pair with the solvent determine the unique properties of these systems. ${ }^{22}$ The volumetric and acoustic properties of electrolytic and nonelectrolytic solutions have proved particularly informative in elucidating the various solute-solvent interactions that exist in these solutions. ${ }^{23-29}$ Acoustic, volumetric and osmotic data for IL-containing systems are of great relevance in assessing intermolecular interactions between the IL and solvent and also for the development of thermodynamic models specific to IL-containing systems.

To date, a number of researchers have studied the thermophysical properties of aqueous solutions of ILs systems. ${ }^{30-48}$ For the understanding of molecular interactions between the IL and water, volumetric properties at different temperatures ranging from 293.15 to $313.15 \mathrm{~K}$ and acoustic and osmotic properties at $298.15 \mathrm{~K}$ for an aqueous solution of 1-ethyl-3methylimidazolium bromide $([\mathrm{Emim}][\mathrm{Br}])$ and the osmotic coefficient at 298.15 K for an aqueous solution of 1-butyl-3methylimidazolium chloride $([\mathrm{Bmim}][\mathrm{Cl}])$ in the dilute concentration region are used together with data from our previous work. ${ }^{49}$ The experimental data are used to obtain the isentropic compressibility $\left(\beta_{\mathrm{S}}\right)$ of solutions. The apparent molar volume $\left(\phi_{\mathrm{V}}\right)$ and compressibility $\left(\phi_{\mathrm{K}_{\mathrm{S}}}\right)$, activity, and activity coefficients of the IL are evaluated at different concentrations. The data of the limiting partial molar volume and compressibility of ILs and their concentration variation are examined to study the effect due to IL-water and IL-IL interactions. Experimental osmotic and activity coefficients are compared against the DebyeHückel and Pitzer models. The activity data are used to obtain the hydration number and the osmotic second virial coefficients of ionic liquids. The osmotic and activity data for the studied 
TABLE 1: Density and Volumetric Properties of Aqueous Solutions of [Emim][Br]

\begin{tabular}{|c|c|c|c|c|c|c|}
\hline $\begin{array}{c}m \\
/ \mathrm{mol} \cdot \mathrm{kg}^{-1}\end{array}$ & $\begin{array}{c}\rho \\
/ \mathrm{kg} \cdot \mathrm{m}^{-3}\end{array}$ & $\begin{array}{c}10^{-3} \cdot \phi_{\mathrm{V}} \\
/ \mathrm{mm}^{3} \cdot \mathrm{mol}^{-1}\end{array}$ & $\begin{array}{c}10^{-3} \cdot \bar{V}_{2} \\
/ \mathrm{mm}^{3} \cdot \mathrm{mol}^{-1}\end{array}$ & $\begin{array}{c}10^{-3} \cdot \bar{V}_{1} \\
/ \mathrm{mm}^{3} \cdot \mathrm{mol}^{-1}\end{array}$ & $\begin{array}{l}10^{4} \alpha \\
/ \mathrm{K}^{-1}\end{array}$ & $\begin{array}{c}10^{6} \phi_{\mathrm{E}} \\
/ \mathrm{m}^{3} \cdot \mathrm{mol}^{-1} \cdot \mathrm{K}^{-1}\end{array}$ \\
\hline \multicolumn{7}{|c|}{$T=293.15 \mathrm{~K}$} \\
\hline 0.00000 & 0.99821 & & & 18.047 & 2.125 & \\
\hline 0.04154 & 1.00046 & 190.93 & 190.62 & 18.047 & 2.099 & 0.040 \\
\hline 0.08422 & 1.00273 & 190.50 & 189.77 & 18.048 & 2.096 & 0.040 \\
\hline 0.13082 & 1.00533 & 190.00 & 188.80 & 18.050 & 2.155 & 0.041 \\
\hline 0.17084 & 1.00750 & 189.59 & 187.97 & 18.052 & 2.177 & 0.041 \\
\hline 0.21279 & 1.00970 & 189.18 & 187.11 & 18.055 & 2.147 & 0.041 \\
\hline 0.25638 & 1.01202 & 188.75 & 186.20 & 18.059 & 2.268 & 0.043 \\
\hline 0.30323 & 1.01442 & 188.30 & 185.25 & 18.064 & 2.257 & 0.043 \\
\hline 0.35442 & 1.01709 & 187.81 & 184.20 & 18.070 & 2.395 & 0.045 \\
\hline 0.39772 & 1.01932 & 187.40 & 183.31 & 18.076 & 2.453 & 0.046 \\
\hline 0.44346 & 1.02174 & 186.95 & 182.37 & 18.084 & 2.188 & 0.041 \\
\hline \multicolumn{7}{|c|}{$T=298.15 \mathrm{~K}$} \\
\hline 0.00000 & 0.99705 & & & 18.068 & 2.567 & \\
\hline 0.04154 & 0.99928 & 191.15 & 190.86 & 18.068 & 2.548 & 0.049 \\
\hline 0.08422 & 1.00153 & 190.72 & 190.00 & 18.069 & 2.570 & 0.049 \\
\hline 0.13082 & 1.00410 & 190.24 & 189.03 & 18.071 & 2.603 & 0.050 \\
\hline 0.17084 & 1.00624 & 189.83 & 188.21 & 18.073 & 2.622 & 0.050 \\
\hline 0.21279 & 1.00846 & 189.41 & 187.34 & 18.076 & 2.618 & 0.050 \\
\hline 0.25638 & 1.01073 & 188.99 & 186.44 & 18.080 & 2.688 & 0.051 \\
\hline 0.30323 & 1.01316 & 188.54 & 185.48 & 18.085 & 2.705 & 0.051 \\
\hline 0.35442 & 1.01576 & 188.05 & 184.44 & 18.091 & 2.795 & 0.053 \\
\hline 0.39772 & 1.01795 & 187.65 & 183.56 & 18.097 & 2.808 & 0.053 \\
\hline 0.44346 & 1.02055 & 187.17 & 182.57 & 18.105 & 2.701 & 0.051 \\
\hline \multicolumn{7}{|c|}{$T=303.15 \mathrm{~K}$} \\
\hline 0.00000 & 0.99565 & & & 18.093 & 3.010 & \\
\hline 0.04154 & 0.99789 & 191.42 & 191.13 & 18.094 & 2.998 & 0.057 \\
\hline 0.08422 & 1.00014 & 190.99 & 190.28 & 18.094 & 3.045 & 0.058 \\
\hline 0.13082 & 1.00270 & 190.50 & 189.31 & 18.096 & 3.054 & 0.058 \\
\hline 0.17084 & 1.00484 & 190.10 & 188.48 & 18.098 & 3.069 & 0.058 \\
\hline 0.21279 & 1.00706 & 189.68 & 187.62 & 18.101 & 3.090 & 0.059 \\
\hline 0.25638 & 1.00928 & 189.26 & 186.73 & 18.105 & 3.110 & 0.059 \\
\hline 0.30323 & 1.01166 & 188.81 & 185.77 & 18.110 & 3.154 & 0.060 \\
\hline 0.35442 & 1.01424 & 188.34 & 184.73 & 18.116 & 3.197 & 0.060 \\
\hline 0.39772 & 1.01643 & 187.93 & 183.85 & 18.123 & 3.164 & 0.060 \\
\hline 0.44346 & 1.01891 & 187.47 & 182.89 & 18.130 & 3.217 & 0.060 \\
\hline \multicolumn{7}{|c|}{$T=308.15 \mathrm{~K}$} \\
\hline 0.00000 & 0.99404 & & & 18.123 & 3.455 & \\
\hline 0.04154 & 0.99634 & 191.72 & 191.43 & 18.123 & 3.450 & 0.066 \\
\hline 0.08422 & 0.99853 & 191.30 & 190.59 & 18.124 & 3.523 & 0.067 \\
\hline 0.13082 & 1.00109 & 190.81 & 189.62 & 18.126 & 3.506 & 0.067 \\
\hline 0.17084 & 1.00323 & 190.40 & 188.79 & 18.128 & 3.518 & 0.067 \\
\hline 0.21279 & 1.00539 & 189.99 & 187.93 & 18.131 & 3.565 & 0.068 \\
\hline 0.25638 & 1.00765 & 189.57 & 187.03 & 18.134 & 3.533 & 0.067 \\
\hline 0.30323 & 1.00999 & 189.13 & 186.08 & 18.139 & 3.605 & 0.068 \\
\hline 0.35442 & 1.01253 & 188.65 & 185.04 & 18.146 & 3.600 & 0.068 \\
\hline 0.39772 & 1.01480 & 188.23 & 184.14 & 18.152 & 3.522 & 0.066 \\
\hline 0.44346 & 1.01729 & 187.77 & 183.17 & 18.159 & 3.734 & 0.070 \\
\hline \multicolumn{7}{|c|}{$T=313.15 \mathrm{~K}$} \\
\hline 0.00000 & 0.99222 & & & 18.156 & 3.903 & \\
\hline 0.04154 & 0.99445 & 192.08 & 191.80 & 18.156 & 3.905 & 0.075 \\
\hline 0.08422 & 0.99662 & 191.67 & 190.96 & 18.157 & 4.003 & 0.077 \\
\hline 0.13082 & 0.99918 & 191.17 & 189.99 & 18.159 & 3.961 & 0.076 \\
\hline 0.17084 & 1.00130 & 190.77 & 189.16 & 18.161 & 3.969 & 0.076 \\
\hline 0.21279 & 1.00346 & 190.36 & 188.29 & 18.164 & 4.042 & 0.077 \\
\hline 0.25638 & 1.00571 & 189.93 & 187.39 & 18.168 & 3.959 & 0.075 \\
\hline 0.30323 & 1.00803 & 189.50 & 186.44 & 18.173 & 4.059 & 0.077 \\
\hline 0.35442 & 1.01059 & 189.02 & 185.39 & 18.179 & 4.006 & 0.076 \\
\hline 0.39772 & 1.01286 & 188.59 & 184.49 & 18.185 & 3.882 & 0.073 \\
\hline 0.44346 & 1.01518 & 188.16 & 183.54 & 18.193 & 4.255 & 0.080 \\
\hline
\end{tabular}

ILs in aqueous solutions are compared with the Debye-Hückel limiting law. The data acquired have been used to understand the water-ionic liquid interactions and the effect of the ionic liquid on the water structure.

\section{Experimental Section}

$[$ Emim $][\mathrm{Br}]$ (purity $>98 \%$ ) and $[\mathrm{Bmim}][\mathrm{Cl}]$ (purity $>99 \%$ ) were acquired from Solchemar and Merck, respectively, and used without further purification. The concentrations of the IL solutions in water were prepared on a molality basis. The water used for the solutions was freshly prepared, doubly quartz distilled. The uncertainty in composition was found to be on the order of $\pm 1 \times 10^{-4} \mathrm{~mol} \cdot \mathrm{kg}^{-1}$. The water content in the ILs was determined using a microprocessor-based automatic Karl-Fischer Titrator, TKF-55, Chemito, from the M/s Toshniwal company. Pyridine-free Aquanil-5 Karl-Fischer reagent 


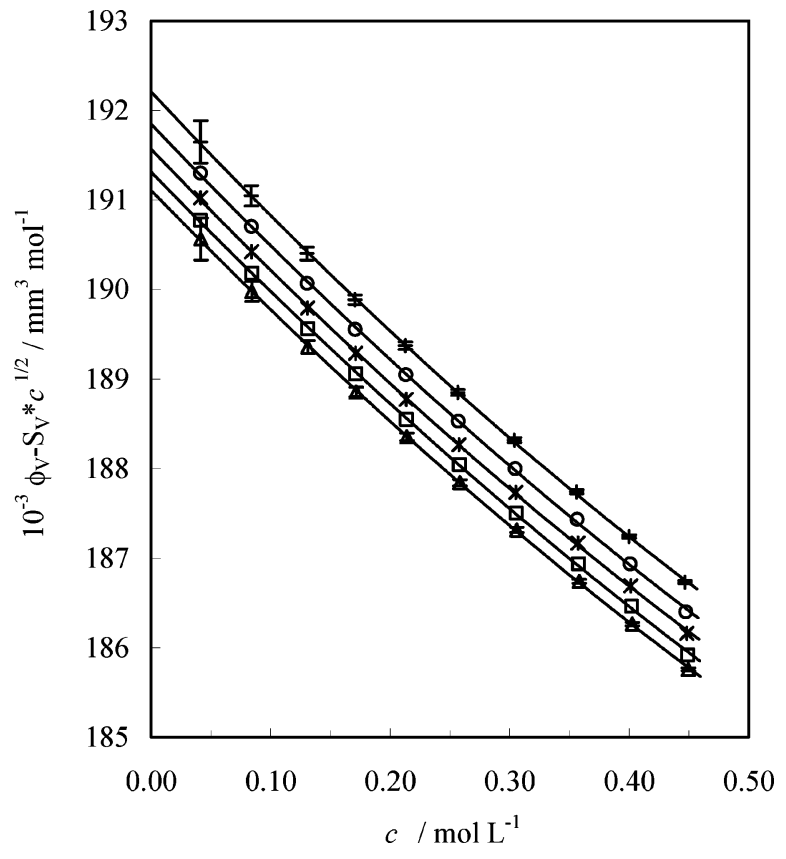

Figure 1. The variation of the parameter $\left(\phi_{\mathrm{V}}-S_{\mathrm{V}} c^{1 / 2}\right)$ as a function of the concentration $(c)$ of $[\mathrm{Emim}][\mathrm{Br}]$ at $293.15 \mathrm{~K}, \Delta ; 298.15 \mathrm{~K}, \square$; $303.15 \mathrm{~K}, * ; 308.15 \mathrm{~K}, \diamond$; and $313.15 \mathrm{~K}, \times$.

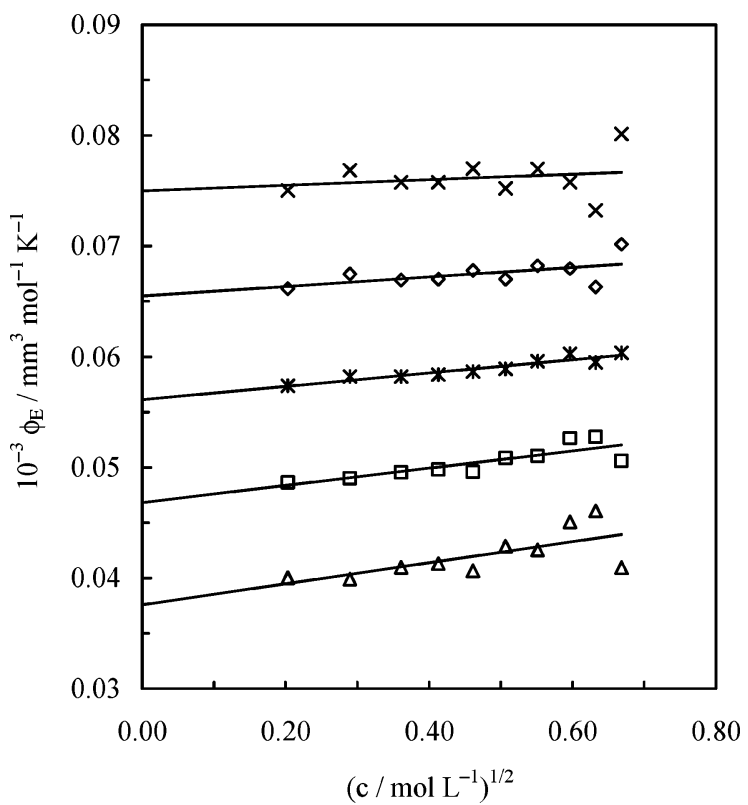

Figure 2. The variation of the apparent molar expansivity $\left(\phi_{\mathrm{E}}\right)$ as a function of concentration $(c)$ of $[\mathrm{Emim}][\mathrm{Br}]$ at $293.15 \mathrm{~K}, \Delta ; 298.15$ $\mathrm{K}, \square ; 303.15 \mathrm{~K}, * ; 308.15 \mathrm{~K}, \diamond$; and $313.15 \mathrm{~K}, \times$.

of Thomas Baker was used for analysis. The reagent was standardized with a solution of water in methanol. The instrument is able to detect the water content on the order of \pm 2 ppm in organic solvents. The water content in [Emim] $[\mathrm{Br}]$ and $[\mathrm{Bmim}][\mathrm{Cl}]$ was found to be 2.98 and $0.94 \%$ by mass, respectively. This water content in ILs was taken into account during the preparation of the aqueous solutions.

The densities of an aqueous solution of [Emim][Br] were measured at regular temperature intervals of $5 \mathrm{~K}$ from 293.15 to $313.15 \mathrm{~K}$ using a high-precision Anton PAAR (DMA 60/ 602) digital density meter. The temperature constancy of the vibrating tube was better than $\pm 0.02 \mathrm{~K}$ as it was maintained constant by circulating water through a Julabo cryostat having a temperature stability of $\pm 0.01 \mathrm{~K}$. After applying humidity and laboratory pressure corrections, the accuracy in the density

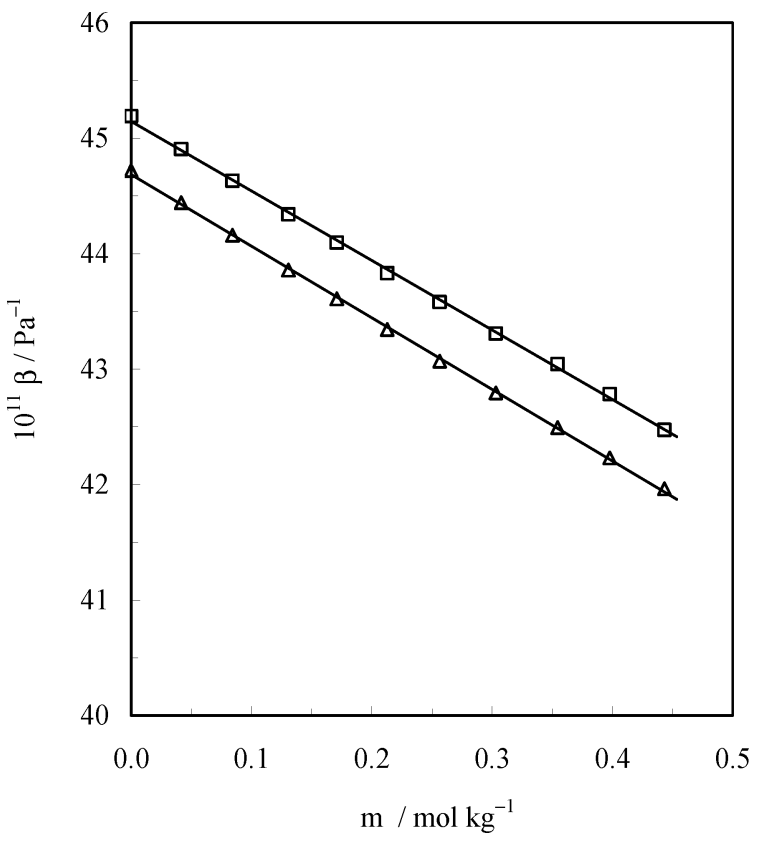

Figure 3. The variation of compressibility as a function of the molality (m) of $[$ Emim] $][\mathrm{Br}]$ at $T=298.15 \mathrm{~K}: \beta_{\mathrm{S}}, \Delta ; \beta_{\mathrm{T}}, \square$.

values was found to be on the order of $\pm 5 \times 10^{-3} \mathrm{~kg} \cdot \mathrm{m}^{-3}$. The reliability of the density data obtained was ascertained by making measurements of aqueous binary solutions of alkali halides and comparing the data with literature. ${ }^{50}$ Similarly, the calculated apparent molar volume $\left(\phi_{\mathrm{V}}\right)$ of $\mathrm{NaCl}$ or $\mathrm{KCl}$ in aqueous solutions at $T=298.15 \mathrm{~K}$, plotted in the form of $\phi_{V}-$ $1.868 \sqrt{c}$ against the concentration of salt $(c)$ in $\mathrm{mol} \cdot \mathrm{L}^{-1}$, when extrapolated to infinite dilution, yields limiting apparent molar volumes which are in good agreement with the literature data. ${ }^{51}$

The speed of sound measurements were carried out for an aqueous solution of $[\mathrm{Emim}][\mathrm{Br}]$ at $T=298.15 \pm 0.02 \mathrm{~K}$ at a fixed frequency of $2 \mathrm{MHz}$ (M/s Mittle Enterprises). Good quality thermostating (temperature inside of the cell $\pm 0.05 \mathrm{~K}$ ) to maintain constant temperature was achieved by circulating water by means of a Julabo thermostat having an accuracy of \pm 0.02 $\mathrm{K}$ around the cell. The reliability of the measurements was checked by obtaining sound velocity data for water at $T=$ $298.15 \mathrm{~K}\left(1497.6 \mathrm{~m} \cdot \mathrm{s}^{-1}\right)$, which agree well with the reported literature data. ${ }^{52}$ The standard deviation for the speed of sound measurement values was found to be on the order of $\pm 0.3 \mathrm{~m} \cdot \mathrm{s}^{-1}$, obtained after repeated measurements.

The osmotic coefficients of an aqueous solution of [Emim]$[\mathrm{Br}]$ and $[\mathrm{Bmim}][\mathrm{Cl}]$ were determined using a KNAUER K-7000 vapor pressure osmometer at $298.15 \pm 0.001 \mathrm{~K}$. The details about the calibration of the vapor pressure osmometer are reported elsewhere..$^{53-55}$

\section{Results}

3.1. Volumetric Properties: The density data $(\rho)$ at a temperature interval of $5 \mathrm{~K}$ from 293.15 to $313.15 \mathrm{~K}$ for an aqueous solution of $[\mathrm{Emim}][\mathrm{Br}]$ in the concentration range of 0.04 to $0.4 \mathrm{~mol} \cdot \mathrm{kg}^{-1}$ are reported in Table 1 . The apparent molar volumes $\left(\phi_{\mathrm{V}}\right)$ as a function of molality of the IL were calculated using eq 1

$$
\phi_{\mathrm{V}}=\left(\frac{M_{2}}{\rho}\right)+\left[\frac{\left(\rho_{0}-\rho\right)}{m \rho \rho_{0}}\right]
$$


TABLE 2: Speed of Sound, Compressibilities, and Internal Pressure Data for Aqueous Solutions of $[\mathrm{Emim}][\mathrm{Br}]$ at $T=298.15$ $\mathbf{K}$

\begin{tabular}{cccccc}
\hline $\begin{array}{c}\mathrm{m} \\
/ \mathrm{mol} \cdot \mathrm{kg}^{-1}\end{array}$ & $\begin{array}{c}\mathrm{u} \\
/ \mathrm{m} \cdot \mathrm{s}^{-1}\end{array}$ & $\begin{array}{c}10^{11} \beta_{\mathrm{S}} \\
/ \mathrm{Pa}^{-1}\end{array}$ & $\begin{array}{c}10^{11} \beta_{\mathrm{T}} \\
/ \mathrm{Pa}^{-1}\end{array}$ & $\begin{array}{c}\phi_{\mathrm{K}_{\mathrm{S}}} \\
/ \mathrm{mm}^{3} \cdot \mathrm{MPa}^{-1} \cdot \mathrm{mol}^{-1}\end{array}$ & $\begin{array}{c}\phi_{\mathrm{K}_{\mathrm{T}}} \\
/ \mathrm{mm}^{3} \cdot \mathrm{MPa}^{-1} \cdot \mathrm{mol}^{-1}\end{array}$ \\
\hline 0.00000 & 1497.6 & 44.72 & 45.19 & & \\
0.04154 & 1500.6 & 44.44 & 44.90 & $-6.1 \pm 4.3$ & $-7.4 \pm 4.9$ \\
$/ \mathrm{Pa}^{-5} P_{i}$ & 1716 \\
0.08422 & 1503.7 & 44.16 & 44.63 & $-6.1 \pm 2.1$ & $-5.6 \pm 2.4$ \\
0.13082 & 1506.9 & 43.86 & 44.34 & $-6.1 \pm 1.4$ & $-4.7 \pm 1.6$ \\
0.17084 & 1509.6 & 43.61 & 44.10 & $-5.8 \pm 1.0$ & $-4.2 \pm 1.2$ \\
0.21279 & 1512.5 & 43.34 & 43.83 & $-5.8 \pm 0.8$ & $-4.5 \pm 1.0$ \\
0.25638 & 1515.7 & 43.07 & 43.58 & $-5.9 \pm 0.7$ & $-3.4 \pm 0.8$ \\
0.30323 & 1518.7 & 42.79 & 43.31 & $-5.5 \pm 0.6$ & $-2.3 \pm 0.6$ \\
0.35442 & 1522.1 & 42.49 & 43.04 & $-5.2 \pm 0.5$ & $-2.6 \pm 0.5$ \\
0.39772 & 1525.2 & 42.23 & 42.78 & $-5.4 \pm 0.4$ & $-4.1 \pm 0.5$
\end{tabular}

TABLE 3: Limiting Volume and Compressibility Properties for Aqueous Solutions of [Emim][Br]

\begin{tabular}{cccccccc}
\hline $\begin{array}{c}T \\
/ \mathrm{K}\end{array}$ & $\begin{array}{c}10^{-3} \cdot \phi_{\mathrm{V}}^{0} \\
/ \mathrm{mm}^{3} \cdot \mathrm{mol}^{-1}\end{array}$ & $\begin{array}{c}10^{-3} B_{\mathrm{V}} \\
/ \mathrm{mm}^{6} \cdot \mathrm{mol}^{-2}\end{array}$ & $\begin{array}{c}10^{6} \phi_{\mathrm{E}}^{0} \\
/ \mathrm{m}^{3} \cdot \mathrm{mol}^{-1} \cdot \mathrm{K}^{-1}\end{array}$ & $\begin{array}{c}S_{\mathrm{E}} \\
\mathrm{MPa}_{\mathrm{S}}^{0} / \mathrm{mm}^{3} \cdot \mathrm{mol}^{-1}\end{array}$ & $\begin{array}{c}10^{-3} S_{\mathrm{K}_{\mathrm{S}}} / \mathrm{mm}^{9 / 2} \cdot \\
\mathrm{MPa} \mathrm{mol}^{-1} \cdot \mathrm{mol}^{-3 / 2}\end{array}$ & $\begin{array}{c}\phi_{\mathrm{K}}^{0} / \mathrm{mm}^{3} \cdot \\
\mathrm{MPa}^{-1} \cdot \mathrm{mol}^{-1}\end{array}$ & $\begin{array}{c}10^{-3} S_{\mathrm{K}_{\mathrm{T}}} / \mathrm{mm}^{9 / 2} \cdot \\
\mathrm{MPa}^{-1} \cdot \mathrm{mol}^{-3 / 2}\end{array}$ \\
\hline 293.15 & $190.9 \pm 1.2$ & -11.68 & $0.038 \pm 0.002$ & 0.0095 & & & \\
298.15 & $191.1 \pm 1.2$ & -11.77 & $0.047 \pm 0.002$ & 0.0078 & $-6.6 \pm 6.9$ & 1.8 & $-8.2 \pm 7.6$ \\
303.15 & $191.4 \pm 1.2$ & -11.80 & $0.056 \pm 0.002$ & 0.0060 & & & \\
308.15 & $191.7 \pm 1.2$ & -11.92 & $0.066 \pm 0.002$ & 0.0043 & & & \\
313.15 & $192.0 \pm 1.2$ & -12.02 & $0.075 \pm 0.002$ & 0.0025 & &
\end{tabular}

where $M_{2}$ is the molar mass of the IL in $\mathrm{kg} \cdot \mathrm{mol}^{-1}, m$ is the molality in $\mathrm{mol} \cdot \mathrm{kg}^{-1}$, while $\rho_{0}$ and $\rho$ represent the density values for water and solution, respectively. The errors in $\phi_{\mathrm{V}}$ were obtained using the method of propagation of errors and found to have a maximum value of $\pm 0.23 \times 10^{3} \mathrm{~mm}^{3} \cdot \mathrm{mol}^{-1}$ at the lowest concentration studied. The data of $\phi_{\mathrm{V}}$ at different temperatures for aqueous solutions of [Emim] $[\mathrm{Br}]$ are reported in Table 1 . The $\phi_{\mathrm{V}}$ data can also be expressed as

$$
\phi_{\mathrm{V}}=\phi_{\mathrm{V}}^{0}+S_{\mathrm{V}} \sqrt{c}+B_{\mathrm{V}} c
$$

where $S_{\mathrm{V}}$ is the Debye-Hückel limiting slope $\left(S_{\mathrm{V}}\right.$ values for aqueous solutions of 1:1 electrolytes at different temperatures were taken from the literature ${ }^{55}$ ) and $B_{\mathrm{V}}$ is the deviation parameter. The molality data were converted to molarity for use in eq 2. The smooth extrapolations of the $\left(\phi_{\mathrm{V}}-S_{\mathrm{V}} \sqrt{c}\right)$ data to infinitely dilute solutions enabled us to obtain the limiting apparent molar volume $\left(\phi_{\mathrm{V}}^{0}\right)$ of $[\mathrm{Emim}][\mathrm{Br}]$, as shown in Figure $1 . B_{\mathrm{V}}$ values for aqueous solutions of [Emim] $[\mathrm{Br}]$ are reported in Table 3. The data of $\phi_{\mathrm{V}}$ were further used to calculate the partial molar volumes of the solute $\left(\bar{V}_{2}\right)$ and solvent $\left(\bar{V}_{1}\right)$ using standard equations ${ }^{57}$ and are reported in Table 1.

The isobaric expansivity $\alpha=-(1 / \rho)(\mathrm{d} \rho / \mathrm{d} T)$ data were obtained from different temperature density data for aqueous solutions of [Emim][Br]. The accuracy in the $\alpha$ data is on the order of $\pm 5 \times 10^{-6} \mathrm{~K}^{-1}$. The apparent molar expansivity $\left(\phi_{\mathrm{E}}\right)$ for aqueous solutions of [Emim] $[\mathrm{Br}]$ as a function of concentration were calculated using the standard equation ${ }^{58}$ given below

$$
\phi_{\mathrm{E}}=\left(\frac{M_{2} \alpha}{\rho}\right)+\left[\frac{\left(\alpha \rho_{0}-\alpha_{0} \rho\right)}{m \rho \rho_{0}}\right]
$$

The errors in the apparent molar expansivity were calculated using the method of propagation of errors and were found to be $\pm 0.001 \times 10^{-6} \mathrm{~m}^{3} \cdot \mathrm{mol}^{-1} \cdot \mathrm{K}^{-1}$. The smooth extrapolations of the $\phi_{\mathrm{E}}$ data to infinitely dilute solutions enabled us to obtain the limiting apparent molar expansivity $\left(\phi_{\mathrm{E}}^{0}\right)$ of $[\mathrm{Emim}][\mathrm{Br}]$, as shown in Figure 2.

3.2. Acoustic Properties: The speed of sound data $(u)$ at $T$ $=298.15 \mathrm{~K}$ of an aqueous solution of $[\mathrm{Emim}][\mathrm{Br}]$ in the concentration range of 0.04 to $0.4 \mathrm{~mol} \cdot \mathrm{kg}^{-1}$ are reported in Table
2. The isentropic compressibility $\left(\beta_{\mathrm{S}}\right)$ of solvents and solutions was obtained using the Laplace equation $\beta_{\mathrm{s}}=1 /\left(u^{2} \rho\right)$. The uncertainty in the $\beta_{\mathrm{S}}$ values was obtained using the method of propagation of errors, and it was found to be on the order of $\pm 1.3 \times 10^{-13} \mathrm{~Pa}^{-1}$. The calculations of the isothermal compressibility $\left(\beta_{\mathrm{T}}\right)$ for aqueous solutions of [Emim] $[\mathrm{Br}]$ were made by using $\beta_{\mathrm{S}}, \alpha$, and $C_{\mathrm{p}}$ data and using following expression

$$
\beta_{\mathrm{T}}-\beta_{\mathrm{S}}=\delta=\alpha^{2} T / \sigma=\alpha^{2} T / C_{\mathrm{p}} \rho
$$

The variation of $\alpha$ is the main contributing factor in obtaining $\beta_{\mathrm{T}}$ from $\beta_{\mathrm{S}}$ values. ${ }^{59}$ The three parameters $\delta_{0}, \alpha_{0}$, and $\sigma_{0}$ for the pure water used are $0.47 \times 10^{-11} \mathrm{~Pa}^{-1}, 2.57 \times 10^{-4} \mathrm{~K}^{-1}$, and $4.1675 \mathrm{~J} \cdot \mathrm{K}^{-1} \cdot \mathrm{cm}^{-3}$, respectively, at $298.15 \mathrm{~K}$. The $C_{\mathrm{p}}$ value for the water used for calculations is taken from the literature ${ }^{59}$ as $4.1793 \mathrm{~J} \cdot \mathrm{K}^{-1} \cdot \mathrm{g}^{-1}$, and we assumed that the $C_{\mathrm{p}}$ value of the solvent remains constant in the studied concentration range. The variations of the $\beta_{\mathrm{S}}$ and $\beta_{\mathrm{T}}$ values with the molality of the IL are shown in Figure 3.

The apparent molar isentropic $\left(\phi_{\mathrm{K}_{\mathrm{S}}}\right)$ or isothermal $\left(\phi_{\mathrm{K}_{\mathrm{T}}}\right)$ compressibility of aqueous solutions of [Emim][Br] was calculated using eq 5 as

$$
\phi_{\mathrm{K}}=\left(\frac{M_{2} \beta}{\rho}\right)+\left[\frac{\left(\beta \rho_{0}-\beta^{0} \rho\right)}{m \rho \rho_{0}}\right]
$$

where $\beta^{0}$ and $\beta$ represent the compressibility of pure water and solution, respectively. The errors in the $\phi_{\mathrm{K}_{\mathrm{S}}}$ and $\phi_{\mathrm{K}_{\mathrm{T}}}$ values were obtained using the method of propagation of errors, and they were found to be on the order of \pm 4 and $\pm 5 \mathrm{~mm}^{3} \cdot \mathrm{MPa}^{-1} \cdot \mathrm{mol}^{-1}$ at the lowest concentration studied.

The variations of $\phi_{\mathrm{K}_{\mathrm{S}}}$ and $\phi_{\mathrm{K}_{\mathrm{T}}}$ for aqueous solutions of [Emim][Br] at $298.15 \mathrm{~K}$ as a function of IL molarity $(c)$ are shown in Figure 4. The apparent molar compressibility can also be expressed as

$$
\phi_{\mathrm{K}}=\phi_{\mathrm{K}}^{0}+S_{\mathrm{K}} \sqrt{c}
$$

where $S_{\mathrm{K}}$ is the experimental limiting slope. The smooth extrapolations of the $\phi_{\mathrm{K}}$ data to infinitely dilute solutions enabled us to obtain limiting apparent compressibilities $\left(\phi_{\mathrm{K}}^{0}\right)$. The $\phi_{\mathrm{K}}^{0}$ 


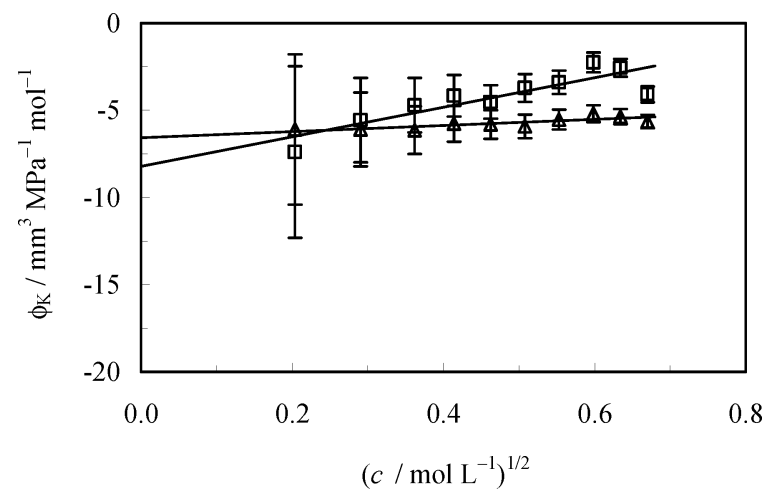

Figure 4. The plot of apparent molar compressibility as a function of the square root of the concentration $(\sqrt{c})$ of [Emim] $[\mathrm{Br}]$ at $T=$ $298.15 \mathrm{~K}: \phi_{\mathrm{K}_{\mathrm{S}}}, \Delta ; \phi_{\mathrm{K}_{\mathrm{T}}}, \square$.

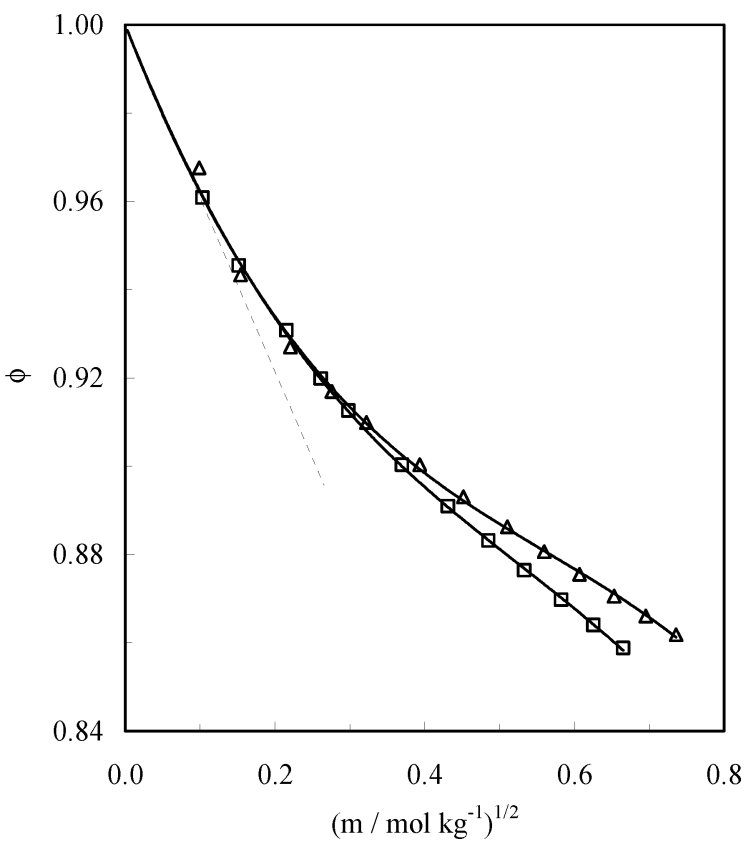

Figure 5. The osmotic coefficients $(\phi)$ of aqueous solutions of [Emim]$[\mathrm{Br}](\square)$ and $[\mathrm{Bmim}][\mathrm{Cl}](\Delta)$. The dotted line $(\cdots)$ represents the Debye-Hückel limiting law.

and experimental slope of $\phi_{\mathrm{K}}$ ( $S_{\mathrm{K}}$ values) for aqueous solutions of [Emim] $[\mathrm{Br}]$ are reported in Table 3 . The errors in the limiting properties are estimated using the method of propagation of errors as reported earlier ${ }^{49}$ and are also included in Table 3.

The energy volume coefficient (internal pressure), that is, $P_{i}$ $=(\mathrm{d} U / \mathrm{d} V)_{\mathrm{T}}$ values at different $[\mathrm{Emim}][\mathrm{Br}]$ concentrations in water were evaluated using the equation of state

$$
P_{i}=(\mathrm{d} U / \mathrm{d} V)_{\mathrm{T}}=T(\mathrm{~d} S / \mathrm{d} V)_{\mathrm{T}}-P=T(\delta P / \delta T)_{\mathrm{V}}-P
$$

Assuming $P(1 \mathrm{~atm})$ is negligible and using $(\delta P / \delta T)_{\mathrm{V}}=(\alpha /$ $\beta_{\mathrm{T}}$ ), the equation of state yields

$$
P_{i}=\left(\alpha / \beta_{\mathrm{T}}\right) T
$$

The estimated error in $P_{i}$ values is on the order of $\pm 25 \times$ $10^{5} \mathrm{~Pa}$. The data of $\beta_{\mathrm{S}}, \beta_{\mathrm{T}}, \phi_{\mathrm{K}_{\mathrm{S}}}, \phi_{\mathrm{K}_{\mathrm{T}}}$, and $P_{i}$ for aqueous solutions of [Emim] $[\mathrm{Br}]$ at $298.15 \mathrm{~K}$ are reported in Table 2.

3.3. Osmotic Properties: The osmotic coefficients $(\phi)$ of aqueous solutions of $[\mathrm{Emim}][\mathrm{Br}]$ and $[\mathrm{Bmim}][\mathrm{Cl}]$ were determined over the concentration range of 0.01 to $\sim 0.5 \mathrm{~mol} \cdot \mathrm{kg}^{-1}$ at 298.15 K and are shown in Figure 5. The water activities

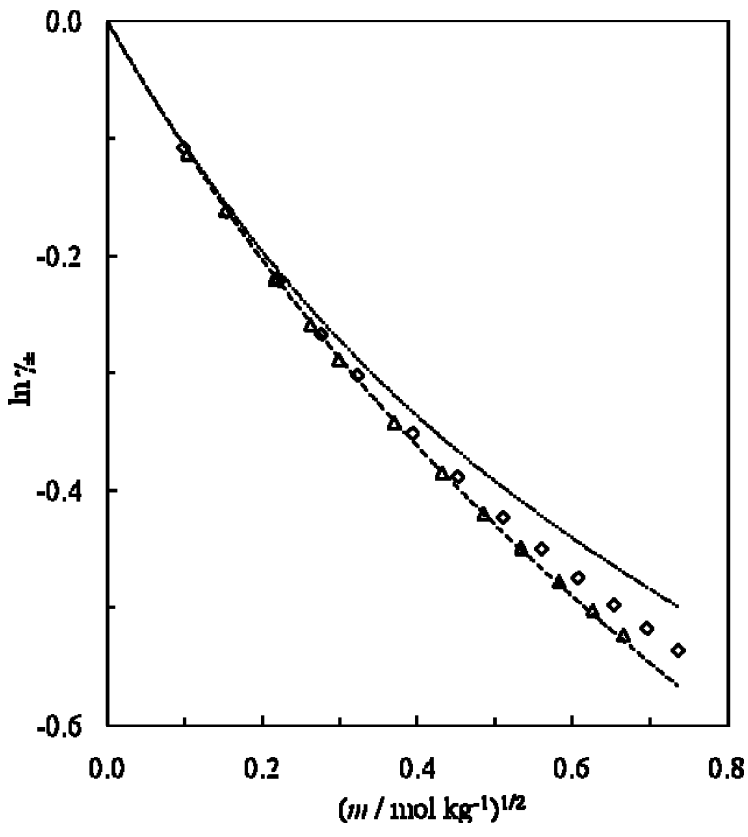

Figure 6. The mean molal activity coefficient of $[\mathrm{Emim}][\mathrm{Br}](\Delta)$ and $[\mathrm{Bmim}][\mathrm{Cl}](\diamond)$ in aqueous solutions at $298.15 \mathrm{~K}$. The mean molal activity coefficient of IL calculated using the Debye-Hückel limiting law is shown by the dotted line $(\cdots)$, whereas those calculated using the Pitzer model are shown by the dashed line (- - -).

$\left(a_{\mathrm{w}}\right)$ were calculated from the experimental osmotic coefficient data by making use of the following expression

$$
\ln a_{\mathrm{w}}=-\phi\left(\frac{x_{2}}{x_{1}}\right)
$$

where $x_{1}$ and $x_{2}$ are the mole fractions of solvent and solute, respectively. The data of the water activities were used to obtain activity coefficients $\left(\gamma_{1}\right)$ of water in aqueous solutions of ILs. The mean molal activity coefficients of ILs $\left(\gamma_{ \pm}\right)$have been calculated using following equation

$$
\ln \gamma_{ \pm}=(\phi-1)+2 \int_{0}^{\sqrt{m}}(\phi-1) d \ln \sqrt{m}
$$

The osmotic coefficient $(\phi)$ can be expressed as

$$
\phi=1-\frac{2.303}{3} A_{\gamma} \sqrt{m}+\sum_{i=2}^{n} A_{i} m^{i / 2}
$$

where $A_{\gamma}$ is the Debye-Hückel limiting slope for aqueous solutions, and its value is 0.5115 at $298.15 \mathrm{~K}$; the coefficients $A_{i}$ can be obtained by the method of least-squares. The equation for $\ln \gamma_{ \pm}$takes the form, after solving the integral, of

$$
\ln \gamma_{ \pm}=-2.303 A_{\gamma} \sqrt{m}+\sum_{i=2}^{n}\left(\frac{i+2}{i}\right) A_{i} m^{i / 2}
$$

The dependence of the mean molal activity coefficient on the IL concentration is shown in Figure 6 for aqueous solutions of $[\mathrm{Emim}][\mathrm{Br}]$ and $[\mathrm{Bmim}][\mathrm{Cl}]$. The activity coefficient data, which have been converted to the mole fraction scale, have been used to estimate the excess Gibbs free-energy change $\left(\Delta G^{\mathrm{E}}\right)$ by using the expression $\Delta G^{\mathrm{E}}=v R T \sum x_{i} \ln \gamma_{i}$, where $x_{i}$ is the mole fraction of component $i$ and $\gamma_{i}$ is the corresponding activity coefficient. Taking into account the hydration effect, the mean 
TABLE 4: Osmotic Coefficient, Water Activity, Activity Coefficient, and Excess Gibbs Free-Energy Data for Aqueous Solutions of $[\mathrm{Emim}][\mathrm{Br}]$ and $[\mathrm{Bmim}][\mathrm{Cl}]$ at 298.15 $\mathbf{K}^{a}$

\begin{tabular}{|c|c|c|c|c|c|}
\hline $\begin{array}{c}\mathrm{m} \\
/ \mathrm{mol} \cdot \mathrm{kg}^{-1}\end{array}$ & $\phi$ & $a_{\mathrm{w}}$ & $\gamma_{1}$ & $\gamma_{ \pm}$ & $\begin{array}{c}\Delta G^{\mathrm{E}} \\
/ \mathrm{J} \cdot \mathrm{mol}^{-1}\end{array}$ \\
\hline \multicolumn{6}{|c|}{$[\mathrm{Emim}][\mathrm{Br}]$} \\
\hline 0.01059 & 0.96083 & 0.99963 & 1.00001 & 0.89345 & -0.14 \\
\hline 0.02296 & 0.94545 & 0.99922 & 1.00004 & 34 & -0.44 \\
\hline 0.04640 & 0.93082 & 0.99845 & 1.00011 & 7 & -1.25 \\
\hline 0.06833 & 0.91986 & 0.99774 & 1.00019 & 0.77236 & -2.18 \\
\hline 0.08885 & 0.91258 & 0.99708 & 1.00027 & 0.74987 & -3.20 \\
\hline 0.13660 & 0.90033 & 099 & 1.00048 & 0.71067 & \\
\hline 0.1857 & 0.89094 & 0.99405 & 1.00071 & 0.68115 & -9.17 \\
\hline 0.2352 & 0.88315 & & 1.00096 & & -12.74 \\
\hline 0.284 & & & & & -16.57 \\
\hline & & & & & -21.09 \\
\hline & 0 & 0.9 & & & -25.61 \\
\hline 0.4 & 0.85881 & 0.98 & 1. & 0.59320 & -30.24 \\
\hline \multicolumn{6}{|c|}{ [Bmi } \\
\hline 0.00 & 0.96 & 0.99966 & 1.00001 & 0.8 & -0.13 \\
\hline 0.023 & 0.943 & 0.99919 & 1.00005 & & -0.45 \\
\hline 0.04853 & 0.92702 & 0.99838 & 1.00013 & 0.80176 & -1.29 \\
\hline 0.07628 & 0.91697 & 0.99748 & 1.00022 & 0.76606 & -2.51 \\
\hline & & & & & -3.94 \\
\hline 0. & 0.900 & 099 & 1.00 & 0.7 & -6.97 \\
\hline 0. & 0.89 & 099 & 1.00 & $0.6^{\prime}$ & -10.30 \\
\hline 0. & 0.886 & 0.99 & 1.00102 & 0.65 & -14.42 \\
\hline 0. & 0.880 & 0.99011 & 1.00 & 0.63 & -18.57 \\
\hline 0.3682 & 0.87551 & 0.98845 & 1.00157 & 0.62265 & -23.10 \\
\hline 0.42655 & 0.87054 & 0.98671 & 1.00187 & 0.60855 & -28.13 \\
\hline & 0.86605 & 0.98502 & 1.00219 & 0.59638 & -33.25 \\
\hline 0.54126 & 0.86185 & 0.98333 & 1.00251 & 0.58541 & -38.59 \\
\hline
\end{tabular}

${ }^{a}$ Note: Subscripts 1 and 2 correspond to solute and solvent, respectively.

molal activity coefficient of electrolytes in aqueous solutions can be expressed as ${ }^{57,60}$

$$
\begin{aligned}
\ln \gamma_{ \pm}=-\frac{A_{\gamma} \sqrt{m}}{1+0.3286 a \sqrt{I}}-\frac{h}{v} \log a_{\mathrm{w}}- \\
\log [1-0.018(h-v) m]
\end{aligned}
$$

Here, $a$ is the distance of the closest approach of oppositely charged ions, and $h$ is the hydration number of the electrolyte. The data of $\phi, a_{\mathrm{w}}, \gamma_{1}, \gamma_{ \pm}$, and $\Delta G^{\mathrm{E}}$ for aqueous solutions of $[$ Emim $][\mathrm{Br}]$ and $[\mathrm{Bmim}][\mathrm{Cl}]$ are reported in Table 4.

Recently, we reported an analysis of activity and heat data to obtain the partial molar entropies for aqueous solutions of model compounds such as 18-crown-6, 15-crown-5, and $\alpha$ cyclodextrin at $298.15 \mathrm{~K} \cdot{ }^{61-63}$ Similar methodology is being used here to obtain the partial molar entropies of the solute and solvent for aqueous solutions of [Bmim][Cl] at $298.15 \mathrm{~K}$ for which the literature enthalpy data ${ }^{64}$ and the Gibbs free-energy data obtained from activities are processed in the following way. The relative apparent molar enthalpy $\phi_{\mathrm{L}}$ at different concentrations of $[\mathrm{Bmim}][\mathrm{Cl}]$ were taken from the literature and utilized further to obtain the heat of mixing per mole of solution $\left(\Delta H_{\text {mix }}\right)$ using the equation ${ }^{65}$

$$
\frac{\Delta H_{\text {mix }}}{n_{1}+n_{2}}=x_{2}\left(\phi_{\mathrm{L}}-L_{2}\right)
$$

where $n_{1}$ and $n_{2}$ are the number of moles of solvent (55.51) and of $[\mathrm{Bmim}][\mathrm{Cl}]$, respectively, while $L_{2}$ is relative partial molar heat content of pure solute, which is the molar solution enthalpy at infinite dilution but with opposite sign $\left(L_{2}\right.$ is taken from the literature as $-16030 \mathrm{~J} \mathrm{~mol}^{-1}$ at $298.15 \mathrm{~K}$, or it can

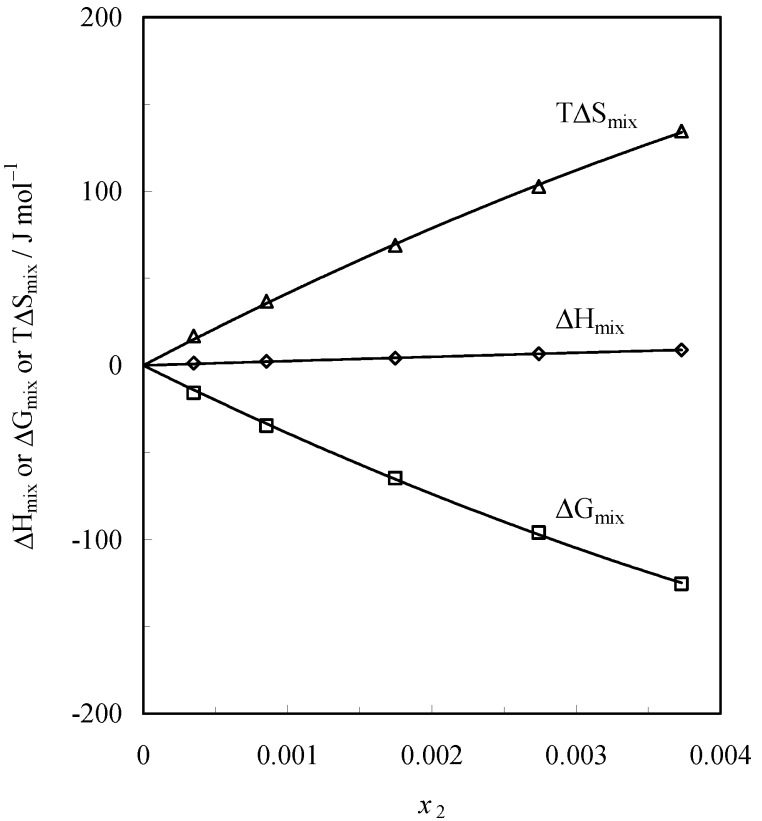

Figure 7. The mixing thermodynamic properties for aqueous solutions of $[\mathrm{Bmim}][\mathrm{Cl}]$ at $298.15 \mathrm{~K}$.

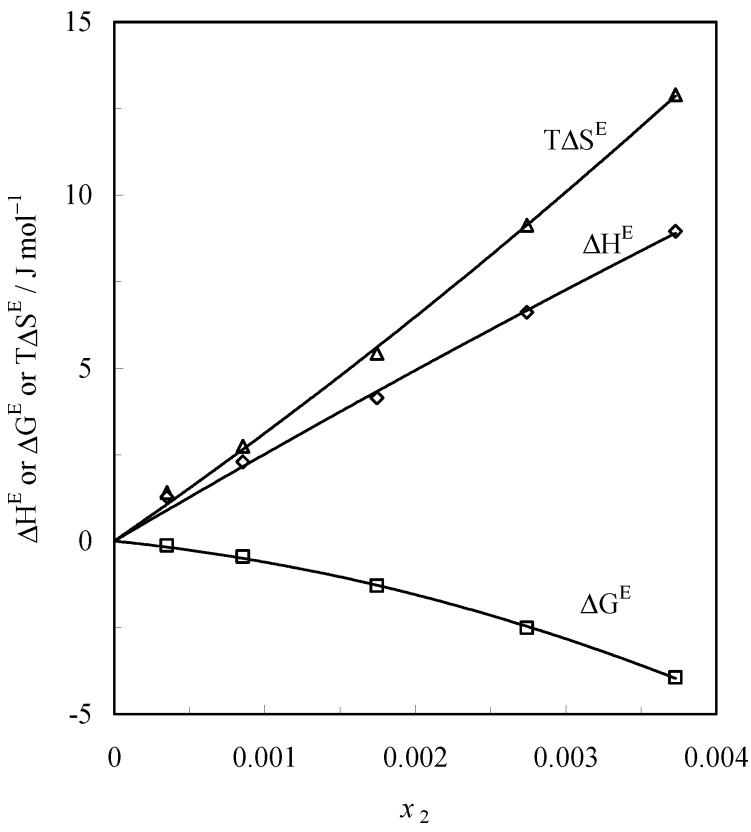

Figure 8. The excess thermodynamic properties for aqueous solutions of $[\mathrm{Bmim}][\mathrm{Cl}]$ at $298.15 \mathrm{~K}$.

also be obtained by plotting data of $\bar{L}_{2}$, that is, the relative partial molar heat content of the solute, against $n_{1} / n_{2}$ and the appropriate extrapolation to the zero value of $n_{1} / n_{2}$ ). The $x_{2}$ is the mole fraction of $[\mathrm{Bmim}][\mathrm{Cl}]$. The data of $\Delta H_{\text {mix }}$ and $\Delta G_{\text {mix }}$ were combined to obtain $T \Delta S_{\operatorname{mix}}$ values at different concentrations using

$$
\Delta G_{\mathrm{mix}}=\Delta H_{\mathrm{mix}}-T \Delta S_{\mathrm{mix}}
$$

The variations of the $\Delta H_{\text {mix }}, \Delta G_{\text {mix }}$, and $T \Delta S_{\text {mix }}$ values with the mole fractions of $[\mathrm{Bmim}][\mathrm{Cl}]$ are shown in Figure 7. Similarly, the excess entropy values at different $[\mathrm{Bmim}][\mathrm{Cl}]$ concentrations were evaluated, and their variations with the mole fractions of $[\mathrm{Bmim}][\mathrm{Cl}]$ are shown in Figure 8 . The relative partial molar heat content of the solvent $\left(\bar{L}_{1}\right)$ and $[\mathrm{Bmim}][\mathrm{Cl}]$ $\left(\bar{L}_{2}\right)$ values were determined using the following equations ${ }^{65}$ 


$$
\begin{aligned}
& \bar{L}_{1}=-\frac{m^{3 / 2}}{55.51 v}\left(\frac{\partial \phi_{\mathrm{L}}}{\partial m^{1 / 2}}\right)_{\mathrm{T}, \mathrm{P}, \mathrm{n}_{1}} \\
& \bar{L}_{2}=\phi_{\mathrm{L}}+\frac{m^{1 / 2}}{v}\left(\frac{\partial \phi_{\mathrm{L}}}{\partial m^{1 / 2}}\right)_{\mathrm{T}, \mathrm{P}, \mathrm{n}_{1}}
\end{aligned}
$$

where $v$ is the number of ions produced upon dissociation of the electrolyte.

Since the partial molar enthalpies of the solvent water and $[\mathrm{Bmim}][\mathrm{Cl}]$ are available, the calculations of the partial molar entropies of the solvent $\left(\bar{S}_{1}-S_{1}^{0}\right)$ and solute $\left(\bar{S}_{2}-S_{2}^{0}\right)$ have been made using the relations ${ }^{65-67}$

$$
\begin{gathered}
\left(\bar{S}_{1}-S_{1}^{0}\right)=\frac{\bar{L}_{1}}{T}-R \ln a_{1} \\
\left(\bar{S}_{2}-S_{2}^{0}\right)=\frac{\left(\bar{L}_{2}-L_{2}\right)}{T}-v R \ln a_{2}
\end{gathered}
$$

where $S_{1}^{0}$ is molar entropy of pure liquid water and $S_{2}^{0}$ is molar entropy of solute in a hypothetical ideal solution of unit mole fraction. The excess partial molar entropies of the solvent $\left(\bar{S}_{1}\right.$ $\left.-S_{1}^{0}\right)^{\mathrm{E}}$ and solute $\left(\bar{S}_{2}-S_{2}^{0}\right)^{\mathrm{E}}$ were further evaluated using the following equations ${ }^{65-67}$

$$
\begin{gathered}
\left(\bar{S}_{1}-S_{1}^{0}\right)^{\mathrm{E}}=\frac{\bar{L}_{1}}{T}-R \ln \gamma_{1} \\
\left(\bar{S}_{2}-S_{2}^{0}\right)^{\mathrm{E}}=\frac{\left(\bar{L}_{2}-L_{2}\right)}{T}-v R \ln \gamma_{2}
\end{gathered}
$$

The values of the parameters (calculated and evaluated) $\phi_{\mathrm{L}}, \bar{L}_{1}$, $\bar{L}_{2}, \Delta H_{\text {mix }}, \Delta G_{\text {mix }}, T \Delta S_{\text {mix }}, \Delta H^{\mathrm{E}}, T \Delta S^{\mathrm{E}},\left(\bar{S}_{1}-S_{1}^{0}\right)^{\mathrm{E}}$, and $\left(\bar{S}_{2}-\right.$ $\left.S_{2}^{0}\right)^{\mathrm{E}}$ are collected in Table 5 for the studied concentrations of $[\mathrm{Bmim}][\mathrm{Cl}]$ in water at $298.15 \mathrm{~K}$. Since the heat data are not available for aqueous solutions of [Emim] $[\mathrm{Br}]$, we are unable to obtain the changes in entropies for this system.

\section{Discussion}

4.1. Volumetric Analysis: It is observed in Table 1 and Figure 1 that the apparent molar volume $\left(\phi_{\mathrm{V}}\right)$ of the [Emim]$[\mathrm{Br}]$ in aqueous solutions decreases with concentration increase for all of the studied temperatures. This is unlike what is observed for aqueous solutions of alkali halides but similar to that for aqueous solutions of tetraalkylammonium salts. ${ }^{68} \mathrm{We}$ expect that $\phi_{\mathrm{V}}$ will go through a minimum at higher concentrations of [Emim] $[\mathrm{Br}]$. The values of the limiting apparent molar volume $\left(\phi_{\mathrm{V}}^{0}\right)$ appear to increase linearly with temperature. Similarly, the $B_{\mathrm{V}}$ parameter (showing deviation from the Debye-Hückel limiting law for volumes) is little effected by changes in the temperature in the studied temperature range. We note in Figure 2 that the apparent molar expansivity $\left(\phi_{\mathrm{E}}\right)$ behavior for the $[\mathrm{Emim}][\mathrm{Br}]$ is similar to aqueous solutions of alkali halides since its variation with concentration is linear with a small positive slope and the limiting apparent molar expansivity $\left(\phi_{\mathrm{E}}^{0}\right)$ values are small. It has been suggested by Millero ${ }^{69}$ and Herrington and Taylor ${ }^{70}$ that aqueous solutions of sodium tetraphenylboron exhibit volumetric properties similar to those of tetraalkylammonium salts in its ion-ion interactions and behave like sodium chloride in dilute concentrations due to ionwater interactions. The aqueous solutions of [Emim][Br] studied here also show both Coulombic interactions as well as hydrophobic hydration effects.
4.2. Acoustic Properties: The examination of Table 3 and Figure 3 shows that the isothermal and isentropic compressibility for aqueous solutions of [Emim] $[\mathrm{Br}]$ decreases with an increase in concentration as expected for electrolytic solutions. The apparent compressibility values for $[\mathrm{Emim}][\mathrm{Br}]$ in aqueous solutions are negative and increase with concentration like simple alkali halides. However, the limiting apparent molar compressibility values are small and negative, similar in magnitude to those of tetraalkylammonium salts. Mathieson and Conway ${ }^{71}$ have interpreted their compressibility measurements for aqueous solutions of tetraalkylammonium salts on the basis of the Frank and Wen model. ${ }^{18}$ They observed that ionic compressibility decreases with increasing ionic volume and that the structure of the solvent around this ion is less compressible than the bulk solvent. Additionally, the intrinsic compressibility of the bulk [Emim $]^{+}$ion may also become important and give positive contribution to $\phi_{\mathrm{K}}^{0}$ values. It can be said that the studied aqueous solutions of [Emim] $[\mathrm{Br}]$ indicate a similarity with normal 1:1 electrolytes as far as the temperature effect is concerned, whereas the behavior is similar to water structure enforcing ions if pressure effects are examined.

There are many attempts to understand ion-solvent interactions in the literature. The utility of partial molal volumes of electrolytes and the ionic vibrational potential has been used to estimate ionic volumes. Noyes ${ }^{72}$ assumes that when an ion is sufficiently large, the $\bar{V}_{\text {electr }}^{0}$ can be calculated from the DrudeNernst $^{61}$ equation

$$
V_{\text {electr }}^{0}=\frac{Z^{2} e^{2}}{2 r D}\left(\frac{\partial \ln D}{\partial P}\right)_{\mathrm{T}}=-\frac{B Z^{2}}{r}
$$

where $B=4.175 \mathrm{~cm}^{3} \cdot \mathrm{mol}^{-1} \cdot \AA^{-1}$ at $298.15 \mathrm{~K}$. Noyes describes a method using the above approach to estimate partial molar volumes of $\mathrm{H}^{+}$ions. Millero ${ }^{74}$ suggested that partial molar volume of an ion at infinite dilution, $\bar{V}_{\text {ion }}^{0}$, can be attributed to the following components

$$
\bar{V}_{\text {ion }}^{0}=\bar{V}_{\text {cryst }}^{0}+\bar{V}_{\text {electr }}^{0}+\bar{V}_{\text {disord }}^{0}+\bar{V}_{\text {caged }}^{0}
$$

This separation is based upon the hydration model used by Gurney, ${ }^{21}$ Frank and Wen, ${ }^{18}$ and Eigen and Wicke ${ }^{75}$ to describe the thermodynamic properties of aqueous solutions.

It is felt that the Gibson relation based on Tait's equation of state yields the excess partial volume of the electrolyte as ${ }^{57,76}$

$$
\bar{V}-V_{\text {cryst }}=-\frac{100 C}{B+P_{i}+P} \frac{\mathrm{d}\left(B+P_{i}\right)}{\mathrm{d} m}
$$

where $\left(\bar{V}-V_{\text {cryst }}\right)$ is, therefore, the change in the volume of mixing of the pure electrolyte liquid and water. In the limit of infinite dilution, eq 24 becomes

$$
\bar{V}^{0}-V_{\text {cryst }}=-\frac{\beta}{d_{0}} \lim _{m \rightarrow 0} \frac{\mathrm{d}\left(B+P_{i}\right)}{\mathrm{d} m}
$$

Mukerjee $^{76}$ has used this approach successfully to estimate electrostriction and intrinsic volumes for electrolytes. The value of the excess volume ( $\left.\bar{V}^{0}-V_{\text {cryst }}\right)$ comes out to be $-10.56 \mathrm{~cm}^{3}$ $\mathrm{mol}^{-1}$. We have calculated the $V_{\text {cryst }}$ value of $201.7 \mathrm{~cm}^{3} \mathrm{~mol}^{-1}$ from the limiting partial molar volume data and the excess volume $\left(\bar{V}^{0}-V_{\text {cryst }}\right)$ by making use of eq 25 . The small volume changes can be attributed to the $\left(\bar{V}_{\text {disord }}^{0}+\bar{V}_{\text {caged }}^{0}\right)$ structural interactions in water. In other words, the volume changes due to Coulombic interactions are small. 
TABLE 5: Thermodynamic Data for Aqueous Solutions of [Bmim][Cl] at $298.15 \mathrm{~K}^{a}$

\begin{tabular}{|c|c|c|c|c|c|c|c|c|}
\hline$\underset{/ \mathrm{mol} \cdot \mathrm{kg}^{-1}}{\mathrm{~m}}$ & $\begin{array}{c}\left(\Delta H_{\text {mix }} \text { or } H^{\mathrm{E}}\right)^{b} \\
\quad / \mathrm{J} \cdot \mathrm{mol}^{-1}\end{array}$ & $\begin{array}{c}\Delta H_{\text {mix }} \text { or } H^{\mathrm{E}} \\
/ \mathrm{J} \cdot \mathrm{mol}^{-1}\end{array}$ & $\begin{array}{c}\phi_{\mathrm{L}} \\
/ \mathrm{J} \cdot \mathrm{mol}^{-1}\end{array}$ & $\begin{array}{c}(T \Delta S)^{\mathrm{E}} \\
/ \mathrm{J} \cdot \mathrm{mol}^{-1} \cdot \mathrm{K}^{-1}\end{array}$ & $\underset{/ \mathrm{J} \cdot \mathrm{mol}^{-1}}{\Delta G_{\text {mix }}}$ & $\begin{array}{c}T \Delta S_{\text {mix }} \\
/ \mathrm{J} \cdot \mathrm{mol}^{-1}\end{array}$ & $\begin{array}{c}\left(S_{1}-S_{1}^{0}\right)^{\mathrm{E}} \\
/ \mathrm{J} \cdot \mathrm{mol}^{-1} \cdot \mathrm{K}^{-1}\end{array}$ & $\begin{array}{c}\left(S_{2}-S_{2}^{0}\right)^{\mathrm{E}} \\
/ \mathrm{J} \cdot \mathrm{mol}^{-1} \cdot \mathrm{K}^{-1}\end{array}$ \\
\hline 0.00971 & 7283 & 1.3 & -8747 & 1.40 & -15.66 & 16.93 & 0.00137 & 17.87 \\
\hline 0.02372 & 5362 & 2.3 & -10668 & 2.74 & -34.57 & 36.86 & 0.00189 & 15.31 \\
\hline 0.04853 & 4734 & 4.1 & -11296 & 5.42 & -64.82 & 68.95 & -0.00070 & 19.15 \\
\hline 0.07628 & 4819 & 6.6 & -11211 & 9.12 & -96.10 & 102.71 & -0.00319 & 21.56 \\
\hline 0.10388 & 4793 & 8.9 & -11237 & 12.88 & -125.55 & 134.49 & 0.00190 & 18.60 \\
\hline
\end{tabular}

${ }^{a}$ Note: The enthalpy, free-energy, and entropy values are reported for per mole of solution. Subscripts 1 and 2 correspond to solute and solvent, respectively ${ }^{b}$ Values are reported for per mole of solute.

4.3. Osmotic and Activity Coefficients Data: It is observed from Figure 5 that osmotic coefficient data follow the DebyeHückel limiting behavior at low concentrations but shows deviations at higher concentrations for both of the ILs studied. A similar effect is observed in the variation of the mean molal activity coefficient, as shown in Figure 6. When the activity coefficient data are compared with those calculated using the Pitzer model, it is found that the agreement is excellent for $[\mathrm{Emim}][\mathrm{Br}]$, but for $[\mathrm{Bmim}][\mathrm{Cl}]$, the experimental values are somewhat higher than those obtained from the Pitzer model; the differences increase with an increase in the concentration for $[\mathrm{Bmim}][\mathrm{Cl}]$ in the studied concentration range. Thus, it seems that the size of the larger cation is responsible for the increased activity coefficient values in the case of $[\mathrm{Bmim}][\mathrm{Cl}]$. It has been shown in the case tetralkylammonium fluoride salts that the mean molal activity coefficient increases with an increase in the size of cation whereas it decreases with an increase in the size of anion on going from fluoride to iodide for tetrapropylammonium salts. ${ }^{78}$ Thus, it seems that the simultaneous effect of an increase of the cation and a decrease of the anion sizes for the two ILs studied shows some compensation effect, but still, a small difference is perceived on the activity coefficient values. The mean molal activity coefficient data of aqueous ionic liquids have been fitted using eq 13, and the hydration numbers obtained are 1.76 and 2.30, respectively, for $[\mathrm{Emim}][\mathrm{Br}]$ and $[\mathrm{Bmim}][\mathrm{Cl}]$. The distance of the closest approach for oppositely charged ions is found to be 0.216 and $0.230 \mathrm{~nm}$, respectively, for [Emim] $[\mathrm{Br}]$ and $[\mathrm{Bmim}]-$ [Cl] in aqueous solutions at $298.15 \mathrm{~K}$. The values of the hydration numbers for these ILs are small compared to those of the alkali halides. Upon comparing the hydration numbers of anions, it is observed that the cation does not get hydrated, and its presence reduces the hydration number of anions. This means that the $B$ zone in the hydration model of Frank and Wen ${ }^{18}$ is more structured than the surface water near the ions, leading to more favored ion-ion interactions. In other words, one can interpret that the imidazolium-based cations exist in aqueous solution having a peripheral hydration similar to that of tetraalkylammonium ions. ${ }^{79}$ This is also supported by the observed values of the distance of the closest approach of ions " $a$ " for $[\mathrm{Bmim}][\mathrm{Cl}]$, which matches well with that obtained in the solid phase ( $a=0.254 \mathrm{~nm}$ for monoclinic structure) from X-ray diffraction studies. ${ }^{77}$ There are many explanations offered about the values of $a$ in the literature, and they are discussed in detail using the Bjerrum ion pair concept to deal with deviations of activity coefficients exhibited in aqueous salt solutions ${ }^{57,60}$

The $\Delta G^{\mathrm{E}}$ values are negative for aqueous solutions of both of the ILs at $298.15 \mathrm{~K}$, indicating the negative deviation from Raoult's law. The data of the Gibbs free-energy change upon mixing $\left(\Delta G_{\text {mix }}\right)$ are also negative over the studied concentration range, showing that mixing is energetically favorable in both cases. Examining Table 5 and Figure 7, it is observed that the mixing process is entropy-dominated and the contribution from heat changes seems to be very small. This can also be observed through the excess properties, as shown in Figure 8 where the excess entropy contribution is more important and dominates the behavior of this system. The estimated excess partial molal entropies of $[\mathrm{Bmim}][\mathrm{Cl}]$ in aqueous solutions are positive and remain approximately constant in the studied concentration region, indicating that the ion pair formation is favored over the hydration of ions, which is also in accordance with the observed small hydration number for this salt. Such a behavior is also observed for large tetraalkylammonium halides, ${ }^{65}$ where the large entropy effect is in qualitative agreement with the Frank and Wen model, ${ }^{18}$ indicating that these ions promote the structure of water. In other words, one can conclude that these ionic liquids behave like tetraalkylammonium halides to a large extent in aqueous solutions.

The relative magnitudes of solute-solute and solute-solvent interactions have been studied for nonelectrolytes contribution in the electrolyte solution using statistical mechanical theories. ${ }^{80}$ In dilute solution, if the Debye-Hückel electrostatic contribution is subtracted from a thermodynamic parameter, for example, $\ln \gamma_{ \pm}$, then the remainder is linear in molality as it would be for a nonelectrolyte. ${ }^{81}$ The mean molal activity coefficient of the solute $\left(\gamma_{ \pm}\right)$in the dilute concentration range can be represented as

$$
\ln \gamma_{ \pm}=-\alpha m^{1 / 2}\left(1+b m^{1 / 2}\right)^{-1}+\varpi m
$$

where $\alpha=1.173 \mathrm{~kg}^{1 / 2} \mathrm{~mol}^{-1 / 2}$ at $25^{\circ} \mathrm{C}$ and $b=1.0 \mathrm{~kg}^{1 / 2} \mathrm{~mol}^{-1 / 2}$ and $\omega$ is the nonelectrolyte solute-solute interaction parameter.

According to McMillan and Mayer ${ }^{82}$

$$
\frac{\pi}{k T}=n+B_{22}^{*} n^{2}+B_{222}^{*} n^{3}+\ldots
$$

where $n$ is the number density of the solute and $B_{22}^{*}$ and $B_{222}^{*}$ are the osmotic second and third virial coefficient for the solutesolute interaction. The Gibbs free energy of solution can be expressed as a function the mole ratio $\bar{m}$ (ratio of moles of solute to solvent) using the equation

$$
\begin{array}{r}
\frac{G}{N_{1} k T}=\frac{\mu_{1}^{0}}{k T}+\frac{\mu_{2}^{0}}{k T} \bar{m}-\bar{m}+\bar{m} \ln \bar{m}+\frac{1}{2} A_{22} \bar{m}^{2}+ \\
\frac{1}{3} B_{222} \bar{m}^{3}+\ldots
\end{array}
$$

where $N_{1}$ is the number of moles of solvent, $k$ is the Boltzmann constant, $T$ is the absolute temperature, and $\mu_{1}^{0}$ and $\mu_{2}^{0}$ are the chemical potentials for pure solvent and solute, respectively, whereas $A_{22}$ and $B_{222}$ are the pair and triplet interaction terms for solute particles.

Hill $^{83}$ has shown that the coefficient $A_{22}$ in eq 28 is related to the osmotic second virial coefficient $B_{22}^{*}$ as

$$
A_{22} v_{1}^{0}=2 B_{22}^{* 0}-\bar{v}_{2}^{0}+b_{11}^{0}
$$


where $v_{1}^{0}$ and $\bar{v}_{2}^{0}$ are the molecular volume of the pure solvent and the partial molecular volume of the solute at infinite dilution, respectively, and $b_{11}^{0}\left(=-B_{11}^{* 0}\right)$ is the solute-solvent cluster integral.

For a 1:1 electrolyte

$$
2 \ln \gamma_{2}^{*}=A_{22} \bar{m}+B_{222} \bar{m}^{2}
$$

where $\gamma_{2}^{*}$ is the nonelectrolyte contribution to the solute activity coefficient. From eqs 26 and $30, \omega=\mathrm{A}_{22} M_{1} / 2\left(M_{1}\right.$ is the molar mass of the solvent in $\mathrm{kg} \mathrm{mol}^{-1}$ ), and thus, from eq 29 and using the relation $b_{11}^{0}=-v_{2}^{0}+k T \kappa_{\mathrm{T}}$, where $\kappa_{\mathrm{T}}$ is the isothermal compressibility coefficient of the pure solvent, one can write

$$
N B_{22}^{* 0}=A_{22} V_{1}^{0} / 2+\bar{V}_{2}^{0}-R T \kappa_{\mathrm{T}} / 2
$$

The value for the solute-solute virial coefficient $\left(N B_{22}^{* 0}\right)$ has been calculated by obtaining the value of $\omega$. The values of $N$ $B_{22}^{* 0}$ for $[\mathrm{Emim}][\mathrm{Br}]$ and $[\mathrm{Bmim}][\mathrm{Cl}]$ are found to be -117.5 and $-42.3 \mathrm{~cm}^{3} \mathrm{~mol}^{-1}$, respectively, in aqueous solutions at $298.15 \mathrm{~K}$. For the $N B_{22}^{* 0}$ values, that is, a measure of the solute-solute virial interaction, when examined, it is seen that the value is a large negative in the case of [Emim] $\mathrm{Br}]$. The negative values of $N B_{22}^{* 0}$ can be interpreted in terms of the hydrophobic association of ions. Such a negative value has also been reported for sodium tetraphenylboron. ${ }^{70}$ Thus, it can be noted that large negative values of $N B_{22}^{* 0}$ in the case of [Emim]$[\mathrm{Br}]$ may be due to a hydrophobic anion. The overall picture of this thermodynamic analysis reveals that the large hydrophobic cations and anions tend to combine with each other to minimize their interaction with water, as suggested by Diamond. ${ }^{22}$

\section{Conclusions}

The analysis of the thermodynamic data on properties concerning volumes, expansivity, and compressibility for aqueous solutions of $[\mathrm{Emim}][\mathrm{Br}]$ reveals that the concentration dependence can be accounted for in terms of the hydrophobic hydration of ions similar to that of aqueous solutions of tetraalkylammonium salts. The limiting properties however indicate a resemblance with aqueous solutions of simple alkali halides. Further, these studies show a small extent of electrostriction and that the ionic cosphere interactions are dominated by ion-dipole interactions. The osmotic and activity data for the studied ILs in aqueous solutions obey the Debye-Hückel limiting law in the limiting concentration region. The higher concentration data profiles show deviations due to ion-ion interactions and the specific role played by the anions. The observed small hydration numbers for these ILs reveal that the low charge density of cations and the their hydrophobic nature is responsible for the formation of the water-structure-enforced ion pairs, which is further supported by the agreement between the distances of the closest approach of ions in aqueous solutions and in the solid phase. Further, these conclusions are also in accordance with the observed large positive entropies for the $[\mathrm{Bmim}][\mathrm{Cl}]$ system. The application of the McMillan-Mayer theory of solutions yielded the osmotic second virial coefficients of these ILs due to the nonelectrolyte contribution in the aqueous electrolyte solutions at $298.15 \mathrm{~K}$. The values for the osmotic second virial coefficients are found to be large and negative. The comparatively more negative value in the case of [Emim][Br] further shows that the hydrophobic nature or competency of both the cation and anion determines the strength of interactions among them in the presence of water.
Acknowledgment. R. L. Gardas acknowledges the financial support from Fundação para a Ciência e a Tecnologia (FCT, Portugal) through his postdoctoral fellowship (SFRH/BPD/ 23246/2005) and also to the authorities of Shivaji University for facilities of experimentation and for hospitality.

\section{References and Notes}

(1) Rogers, R. D.; Seddon, K. R. Science 2003, 302, 792-793.

(2) Earle, M. J.; Esperança, J. M. S. S.; Gilea, M. A.; Lopes, J. N. C.; Rebelo, L. P. N.; Magee, J. W.; Seddon, K. R.; Widegren, J. A. Nature 2006, 439, 831-834.

(3) Wilkes, J. S.; Zaworotko, M. J. Chem. Commun. 1992, 965-967.

(4) Seddon, K. R.; Stark, A.; Torres, M. J. Pure Appl. Chem. 2000, 72, 2275-2287.

(5) Fitchett, B. D.; Knepp, T. N.; Conboy, J. C. J. Electrochem. Soc. 2004, 151, E219-E225.

(6) Pandey, S.; Fletcher, K. A.; Baker, S. N.; Baker, G. A. Analyst 2004, 129, 569-573.

(7) Widegren, J. A.; Laesecke, A.; Magee, J. W. Chem. Commun. 2005 $1610-1612$

(8) Chakrabarty, D.; Chakraborty, A.; Seth, D.; Sarkar, N. J. Phys. Chem. A 2005, 109, 1764-1769.

(9) Gardas, R. L.; Freire, M. G.; Carvalho, P. J.; Marrucho, I. M.; Fonseca, I. M. A.; Ferreira, A. G. M.; Coutinho, J. A. P. J. Chem. Eng. Data 2007, 52, 80-88.

(10) Freire, M. G.; Carvalho, P. J.; Fernandes, A. M.; Marrucho, I. M.; Queimada, A. J.; Coutinho, J. A. P. J. Colloid Interface Sci. 2007, 314, $623-630$.

(11) Hanke, C. G.; Lynden-Bell, R. M. J. Phys. Chem. B 2003, 107, 10873-10878.

(12) Huddleston, J. G.; Visser, A. E.; Reichert, W. M.; Willauer, H. D. Broker, G. A.; Rogers, R. D. Green Chem. 2001, 3, 156-164.

(13) Najdanovic-Visak, V.; Rebelo, L. P. N.; Ponte, M. N. Green Chem. 2005, 7, 443-450.

(14) Fu, D. B.; Sun, X. W.; Pu, J. J.; Zhao, S. Q. J. Chem. Eng. Data 2006, 51, 371-375.

(15) Seddon, K. R. J. Chem. Technol. Biotechnol. 1997, 68, 351-356.

(16) Conway, B. E. Annu. Rev. Phys. Chem. 1966, 17, 481-528.

(17) Collins, K. D. Biophys. Chem. 1997, 72, 65-76.

(18) Frank, H. S.; Wen, W.-Y. Discuss. Faraday Soc. 1957, 24, 133140 .

(19) (a) Desrosiers, N.; Perron, G.; Mathieson, J. G.; Conway, B. E.; Desnoyers, J. E. J. Solution Chem. 1974, 3, 789-806. (b) Avedikian, L.; Perron, G.; Desnoyers, J. E. J. Solution Chem. 1975, 4, 331-346.

(20) (a) Friedman, H. L.; Krishnan, C. V. Water: A Comprehensive Treatise; Franks, F., Ed.; Plenum Press: New York, 1973; Vol. III. (b) Ramanathan, P. S.; Krishnan, C. V.; Friedman, H. L. J. Solution Chem. 1972, 1, 237-262. (c) Friedman, H. L.; Ramanathan, P. S. J. Phys. Chem. 1970, 74, 3756-3765.

(21) Gurney, R. W. Ionic Processes in Solution; McGraw-Hill: New York, 1953.

(22) Diamond, R. M. J. Phys. Chem. 1963, 67, 2513-2517.

(23) Glinski, J. Bull. Acad. Pol. Sci. 1977, 25, 905.

(24) Rohman, N.; Dass, N. N.; Mahiuddin, S. J. Chem. Eng. Data 1999, $44,465-472$.

(25) Abraham, R.; Abdulkhadar, M.; Asokan, C. V. J. Chem. Thermodyn. 2000, 32, 1-16.

(26) Glinski, J.; Keller, B.; Legendziewicz, J.; Samela, S. J. Mol. Struct. 2001, 559, 59-66.

(27) Raju, K.; Rajamannan, B.; Rakkappan, C. J. Mol. Liq. 2002, 100, $113-118$.

(28) Galan, J. J.; Del Castillo, J. L.; Gonzalez-Perez, A.; Czapkiewicz, J.; Rodriguez, J. R. J. Solution Chem. 2003, 32, 919-927.

(29) Wahab, A.; Mahiuddin, S. J. Chem. Eng. Data 2004, 49, 126132.

(30) Gaillon, L.; Sirieix-Plenet, J.; Letellier, P. J. Solution Chem. 2004 $33,1333-1347$

(31) Lu, X.-M.; Xu, W.-G.; Gui, J.-S.; Li, H.-W.; Yang, J.-Z. J. Chem. Thermodyn. 2005, 37, 13-19.

(32) Zafarani-Moattar, M. T.; Shekaari, H. J. Chem. Thermodyn. 2005, 37, 1029-1035

(33) Orchillés, A. V.; González-Alfaro, V.; Miguel, P. J.; Vercher, E.; Martínez-Andreu, A J. Chem. Thermodyn. 2006, 38, 1124-1129.

(34) Liu, W.; Zhao, T.; Zhang, Y.; Wang, H.; Yu, M. J. Solution Chem. 2006, 35, 1337-1346.

(35) Zhang, S.; Li, X.; Chen, H.; Wang, J.; Zhang, J.; Zhang, M. J. Chem. Eng. Data 2004, 49, 760-764.

(36) Rebelo, L. P. N.; Najdanovic-Visak, V.; Visak, Z. P.; Nunes da Ponte, M.; Szydlowski, J.; Cerdeirina, C. A.; Troncoso, J.; Romani, L.; Esperanca, J. M. S. S.; Guedes, H. J. R.; de Sousa, H. C. A. Green Chem. 2004, 6, 369-381. 
(37) Xu, H.; Zhao, D.; Xu, P.; Liu, F.; Gao, G. J. Chem. Eng. Data 2005, 50, 133-135.

(38) Yang, J.-Z.; Lu, X.-M.; Gui, J.-S.; Xu, W.-G.; Li, H.-W. J. Chem. Thermodyn. 2005, 37, 1250-1255.

(39) Gomez, E.; Gonzalez, B.; Dominguez, A.; Tojo, E.; Tojo, J. J. Chem. Eng. Data 2006, 51, 696-701.

(40) Jarosik, A.; Krajewski, S. R.; Lewandowski, A.; Radzimski, P. J. Mol. Liq. 2006, 123, 43-50.

(41) Zhou, Q.; Wang, L.-S.; Chen, H.-P. J. Chem. Eng. Data 2006, 51, 905-908.

(42) Gomez, E.; Gonzalez, B.; Calvar, N.; Tojo, E.; Dominguez, A. J.

Chem. Eng. Data 2006, 51, 2096-2102.

(43) Rodriguez, H.; Brennecke, J. F. J. Chem. Eng. Data 2006, 51, 2145-2155.

(44) Calvar, N.; Gonzalez, B.; Dominguez, A.; Tojo, J. J. Solution Chem. 2006, $35,1217-1225$.

(45) Vercher, E.; Orchillés, A. V.; Miguel, P. J.; Martinez-Andreu, A. J. Chem. Eng. Data 2007, 52, 1468-1482.

(46) Malham, I. B.; Letelliera, P.; Mayaffre, A.; Turmine, M. J. Chem. Thermodyn. 2007, 39, 1132-1143.

(47) (a) Freire, M. G.; Neves, C. M. S. S.; Carvalho, P. J.; Gardas, R. L.; Fernandes, A. M.; Marrucho, I. M.; Santos, L. M. N. B. F.; Coutinho, J. A. P. J. Phys. Chem. B 2007, 111, 13082-13089. (b) Freire, M. G.; Carvalho, P. J.; Gardas, R. L.; Marrucho, I. M.; Santos, L. M. N. B. F.; Coutinho, J. A. P. J. Phys. Chem. B 2008, 112, 1604-1610.

(48) Freire, M. G.; Santos, L. M. N. B. F.; Fernandes, A. M.; Coutinho,

J. A. P.; Marrucho, I. M. Fluid Phase Equilib. 2007, 261, 449-454.

(49) Gardas, R. L.; Dagade, D. H.; Terdale, S. S.; Coutinho, J. A. P.;

Patil, K. J. J. Chem. Thermodyn. In press, doi:10.1016/j.jct.2007.10.007.

(50) Fortier, J.-L.; Leduc, P.-A.; Desnoyers, J. E. J. Solution Chem. 1974 3, 323-349.

(51) Millero, F. J. J. Phys. Chem. 1970, 74, 356-362.

(52) Greenspan, M.; Tschiegg, C. E. J. Res. Natl. Bur. Std. 1957, 59 249-258. 9611

(53) Patil, K.; Pawar, R.; Dagade, D. J. Phys. Chem. A 2002, 106, 9606-

(54) Patil, K. J.; Sargar, A. M.; Dagade, D. H. Indian J. Chem., Sect. A 2002, 41, 1804-1811.

(55) Patil, K.; Dagade, D. J. Solution Chem. 2003, 32, 951-966.

(56) Millero, F. J. Chem. Rev. 1971, 71, 147-176.

(57) Harned, H. S.; Owen, B. B. The Physical Chemistry of Electrolyte Solutions, 3rd ed.; American Chemical Society Monograph Series; Reinhold Publishing Corp.: New York, 1958.

(58) Millero, F. J. Physical Chemistry of Natural Waters; John Wiley \& Sons, Inc.: New York, 2001. 096

(59) Desnoyers, J. E.; Philip, P. R. Can. J. Chem. 1972, 50, 1094-

(60) Robinson, R. A.; Stokes, R. H. Electrolyte Solutions, 2nd ed.; Butterworths: London, 1959.

(61) Dagade, D. H.; Kolhapurkar, R. R.; Terdale, S. S.; Patil, K. J. J. Solution Chem. 2005, 34, 415-426.

(62) Terdale, S. S.; Dagade, D. H.; Patil, K. J. J. Phys. Chem. B 2006, $110,18583-18593$.

(63) Dagade, D. H.; Shetake, P. K.; Patil, K. J. J. Phys. Chem. B 2007, $111,7610-7619$.

(64) Guan, W.; Yang, J.-Z.; Li, L.; Wang, H.; Zhang, Q.-G. Fluid Phase Equil. 2006, 239, 161-165.

(65) Pitzer, K. S.; Brewer, L. Thermodynamics (Revision of Lewis and Randall), 2nd ed.; McGraw Hill Co.: New York, 1961.

(66) Glasstone, S. Thermodynamics for Chemists; Litton Educational Publishing, Inc.: New York, 1947.

(67) Lindenbaum, S. J. Phys. Chem. 1966, 74, 814-820.

(68) (a) Wen, W.-Y.; Saito, S. J. Phys. Chem. 1964, 68, 2639-2644.

(b) Wen, W.-Y.; Saito, S. J. Phys. Chem. 1965, 69, 3569-3574.

(69) Millero, F. J. J. Chem. Eng. Data 1970, 15, 562-566.

(70) Herrington, T. M.; Taylor, C. M. J. Chem. Soc., Faraday Trans. 1 1982, 78, 3409-3415.

(71) Mathieson, J. G.; Conway, B. E. J. Solution. Chem. 1974, 3, 455477

(72) Noyes, R. M. J. Am. Chem. Soc. 1964, 86, 971-979.

(73) Drude, P.; Nernst, W. Z. Phys. Chem. 1894, 15, 79-85.

(74) Millero, F. J. Water and Aqueous Solutions: Structure, Thermodynamics, and Transport Processes; Horne, R. A., Ed.; Wiley-Interscience: New York, 1972

(75) Eigen, M.; Wicke, E. J. Phys. Chem. 1954, 58, 702-714.

(76) (a) Mukerjee, P. J. Phys. Chem. 1961, 65, 740-744. (b) Mukerjee, P. J. Phys. Chem. 1961, 65, 744-746. (c) Mukerjee, P. J. Phys. Chem. 1966, 70, 2708.

(77) Holbrey, J. D.; Reichert, W. M.; Nieuwenhuyzen, M.; Johnston, S.; Seddon, K. R.; Rogers, R. D. Chem. Commun. 2003, 1636-1637.

(78) Wen, W.-Y.; Saito, S.; Lee, C. J. Phys. Chem. 1966, 70, 12441248

(79) Talukdar, H.; Kundu, K. K. J. Phys. Chem. 1992, 96, 970-975.

(80) Herrington, T. M.; Mole, E. L. J. Chem. Soc., Faraday Trans. 1 1982, 78, 213-223.

(81) Herrington, T. M.; Mole, E. L. J. Chem. Soc., Faraday Trans. 1 1982, 78, 2095-2100.

(82) McMillan, W.; Mayer, J. J. Chem. Phys. 1945, 13, 276-305.

(83) Hill, T. L. J. Am. Chem. Soc. 1957, 79, 4885-4890. 